\title{
SIMULATION OF SHALLOW GROUNDWATER FLOW FIELD OF A SMALL BEDROCK ISLAND BASED ON REMOTE SENSE: A CASE STUDY IN WAILINGDING ISLAND, CHINA
}

\author{
XU, H. L. ${ }^{1}-$ DING, Z. B. ${ }^{1 *}-$ WANG, D. Q. $.^{*}-$ DENG, Z. D. ${ }^{1}-$ NI, B. R. ${ }^{1}-$ XU, X. G. ${ }^{2}-$ LIU, Z. X. ${ }^{2}$ \\ - YU, D. H. ${ }^{3}-$ ZHAO, X. L. ${ }^{1}$ \\ ${ }^{I}$ Defense Engineering College, Army Engineering University, Nanjing 210007, China \\ ${ }^{2}$ School of Resources and Geosciences, China University of Mining and Technology \\ Xuzhou 221116, China \\ ${ }^{3}$ Institute of engineering design, Beijing 100043, China \\ *Corresponding authors \\ e-mail: Njwaterdzb@qq.com (Ding, Z. B.);wangdq_cumt@sina.com (Wang, D. Q.) \\ (Received $31^{\text {st }}$ May 2019; accepted $16^{\text {th }}$ Oct 2019)
}

\begin{abstract}
In order to overcome the difficulty in obtaining the initial shallow groundwater level of a small bedrock island and build a better geological body model, the assessment of groundwater potential by remote sense (RS) method was introduced into the shallow groundwater flow field modeling of bedrock islands. And the Wailingding Island in China was taken as the study area. The buried depth (h) of water level was fitted with the remote sensing assessment score of shallow groundwater potential, according to the actual water volume. As a result, the study obtained the formula of the fitting curve, which was $\mathrm{S}=0.427 \mathrm{e}^{0.239 \mathrm{~h}}, \mathrm{R}^{2}=0.8462(\mathrm{P}<0.05)$. Then, it used ENVI software to calculate $\mathrm{h}=(1 / 0.239) \ln (\mathrm{S} / 0.427)$ and evaluate the initial water level of shallow groundwater: $\mathrm{D}=\mathrm{DEM}-\mathrm{h}$. Moreover, the study introduced the value of D into the GMS software as the initial water level for the simulation of the shallow groundwater flow field, overcoming the difficulty in obtaining the water level of shallow groundwater in the bedrock islands. The GMS software was used to establish a simulation model of shallow groundwater flow field based on the hydrogeological data in this study area. Also, it used ENVI software to convert DEM data into TIF files and import them into the GMS software, improving the precision of island geological body simulation. Next, the study attempted to change the initial conditions of the simulation model of the shallow groundwater flow field, such as rainfall, evaporation capacity and so on, to predict the distribution of shallow groundwater flow field at different times. Finally, the actual water yield of springs and wells and the geophysical data were used to verify the results of the simulation, and the accuracy has met the requirement. Therefore, it is possible complete the simulation of the shallow groundwater flow field of a small bedrock island by RS technology and other techniques.

Keywords: the bedrock island, simulation of groundwater flow, remote sensing technology, initial water level, geological modeling by using DEM
\end{abstract}

\section{Introduction}

Water is the source of life. Islands are short of water (McCartney and Houghton-Carr, 2018), and the protection of groundwater is an important factor for environment protection and an indispensable part of environmental assessment. Studying on the flow field distribution and pollutant migration and diffusion of island groundwater, which are helpful to the protection and development of groundwater resources. Due to the different geology, different landform and other factors, there are differences and similarities between the study of terrestrial groundwater and that of islands groundwater. As early as 1995, Li's team used the finite element method of water head and concentration dependence to calculate and simulate the water level, water flow and 
water quality of the pyroclastic pore aquifer of Weizhou island and the basalt pore and fracture aquifer (Li et al., 1995). Then, the basis of the groundwater exploitation planning and the control of seawater intrusion was obtained. In 1998, Person studied and predicted the distribution of groundwater in Nantui island (the United States) between 1977 and 2020, using the sharp-interface model, and discussed the intrusion of seawater (McCartney et al., 1998). Subsequently, with the development of computer software, some corresponding groundwater simulation programs and software came out. Liu's team used Modflow-96 to simulate the distribution of groundwater in China's Jinmen island in 2006 (Liu et al., 2006). The eastern part of the island is dominated by granite and gneiss, while the western part is dominated by laterite. Different parameters are set by the program to evaluate the variation level of the groundwater level and provide a scheme for groundwater utilization. In 2008, Barazzuoli et al. used field and experimental data from 1995-2013 in the coastal region of Tuscany, Italy, and used the FEFLOW numerical simulation software to model and analyze the impact of the natural inflow of groundwater into the sea, rivers and man-made wells, and considered the intrusion of seawater, and obtained the water budget. Wen's team studied the groundwater in Leizhou peninsula in 2013 (McCartney et al., 2018). The shallow aquifer in this area is composed of loose rocks and fissure water in volcanic rock cavities. In 2014, Kadi et al. used GMS software to simulate the flow field of Jeju island. And the island is a volcanic, basalts and pyroclastic rocks. For simulating the groundwater situation (Wen et al., 2013), they used the MODFLOW module simulation analysis of groundwater level and spring water, with the SEAWAT module simulating the analysis of seawater intrusion, according to the water level elevation, stream, salinity and other indicators, assessment of the island of groundwater sustainable ability (Alfaro et al., 2017; Mehdizadeh et al., 2017). Subsequently, Lathashri et al. (2016) also studied coastal areas by using the MODFLOW module and proceeds the module of GMS numerical simulation software. Yi et al. (2016) used GMS software to simulate the discharge and seawater intrusion of groundwater in Bohai Bay in Tianjin, China. He used the FEMWATER module to simulate variable density fluid to generalize groundwater and seawater. Li's team built a groundwater simulation model on the east island of Zhanjiang, China (Teng et al., 2015; Zhou et al., 2017). The island was turned into heterogeneous anisotropic, using the Visual MODFLOW software to simulate solution, combining the actual drilling data. The model can better reflect its groundwater hydrogeological situation, and put forward the following island in deep aquifers and deep aquifer groundwater hydraulic ties with China. They discussed the island's sustainability situation of groundwater, and guided the mining of groundwater. Before some integrated programs and software appear, bedrock island groundwater simulation takes analytical calculation as the mainstream, and its visualization effect is not good, and the simulator must have a high level of programming. With the advent of MODFLOW, Visual MODFLOW, GMS, FEFLOW and other software, it seems that the groundwater simulation becomes simple and process-based. It only needs to carry out a detailed investigation on the groundwater recharge and drainage of bedrock islands and seawater intrusion, as well as the experiment and investigation of geological parameters in the region. Then the study used the software to establish a model to simulate. The generalization of bedrock islands of pyroclastic rocks, basalt pore media, highly weathered granite or gneiss, and simulation of other loose rocks is no problem, in accordance with Darcy's law and the equation of motion of groundwater or twodimensional flow. However, for some bedrock islands, there are mainly bedrock cracks, 
such as granite and gneiss. It should conform to the cubic law of groundwater movement. If the geological body is still to be generalized as a pore model, it is similar to the equivalent porous continuous medium model (Long et al., 1982), and it is necessary to modify the parameters such as lithology, water supply and permeability coefficient in local areas. If the geological body is directly considered as a fracture model, the discrete fracture network seepage model (Mao et al., 1984; Wang et al., 2012) is needed to simulate the fracture flow. If the upper strata of the island dominated by bedrock fissures are weathered to a high degree of loose rocks, and the middle and lower strata are still unweathered bedrock fissures, double or multiple media should be considered. If the geological body is still replaced by the pore model and the MODFLOW, Visual MODFLOW, GMS and FEFLOW are used, then the parameters of stratified strata need to be set, which should conform to the properties of each stratum. If the crack model is used, the crack can be simulated with the TOUGH2 software or GMS+TOUGH2 (Tan et al., 2017). At present, the Lawrence Berkeley laboratory in the United States has introduced TOUGH3 software, which is an upgraded version of TOUGH2, adding the function of coding modification and realizing a wider range of simulation. The MODFLOW-SURFACT module is also a program module that can simulate dual media and fracture well (Tan et al., 2017). The CONNETFLOW is a finite element groundwater simulation software for cracks, in which the NAMMU module is for porous media model and the NAPSAC module is for discrete fracture network seepage model. The software can be applied to dual media. Islands of volcanic islands, loose rocks and highly differentiated bedrock are pore type, whose seepage flow conforms to the movement equation of the groundwater of the heterogeneous anisotropy or transverse isotropy, which can be directly simulated by the MODFLOW program, Visual MODFLOW, GMS or FEFLOW software. Bedrock fissures are dominated or with a low degree of bedrock differentiation. They are fracture type. The movement law of groundwater conforms to the cubic law, which can be simulated by the TOUGH2 software, MODFLOW-SURFACT program module and CONNETFLOW finite element simulation software. If the geological body is a pore-crack type (dual medium or multiple medium), we need to simulate the flow geological model based on the MODFLOW, TOUGH2 software, or SURFACT program module. And the study used the CONNETFLOW finite element simulation software to carry out the coupling between pores and cracks. For the intrusion of the bedrock island seawater, its boundary can be directly delineated by combining geophysical and drilling data with its coastline, using SUTRA software, taking into account MODFLOW flow model combined with MT3DMS solute transport model, or using fault module for simulation.

In the past, researchers studied the groundwater flow field of islands in large scale sea areas or mostly studied the distribution of groundwater flow field of sandy islands. However, the simulation of the groundwater flow field in a small bedrock island has not been well studied. This study mainly aimed at the simulation of the shallow groundwater flow field in a small bedrock island. Groundwater in bedrock islands is mostly stored in the form of "freshwater mushroom" (Pang, 1987, 1988), and there are also "freshwater lens", which is different sand islands. The difficulty of shallow groundwater flow field simulation in bedrock islands lies in the acquisition of hydrogeological parameters, especially in small islands which are short of adequate wells or springs. Zhou et al. (2017) used the MODFOLW model to simulate the Donghai island of Zhanjiang, China. Currently, geophysical techniques were also used to detect groundwater throughout the islands (Rosemary et al., 2009). However, it will 
cost a lot of work in this method. Therefore, the assessment of the shallow groundwater by remote sensing technology was introduced in this paper to solve the problem that it is difficult to obtain the initial water level of the shallow groundwater flow field in the small bedrock islands. And it combined with geophysical exploration technology and other hydrogeological means. Also, it combined with stratigraphic stratification data, and some hydrogeological parameters of the strata. Furthermore, the shallow groundwater flow field simulation of small bedrock islands was realized.

\section{Material and Methods}

\section{Equation of groundwater movement in the bedrock islands}

According to the lithologic characteristics of different bedrock islands, there are different theoretical expressions of groundwater movement. Its specific theory should be based on the island's specific bedrock lithology or stratigraphic lithology to choose different forms. If the bedrock island strata are loose strata, such as the east island of Zhenjiang city (Lu, 2007), and granite and gneiss affected by weathering, unloading, and topographic factors, it can be thought that the geological body can be generalized into non-homogeneous anisotropy or transversely isotropy in this paper. The groundwater motion equation (simplified anisotropic medium) or two-dimensional flow motion equation can be used as (Eq. 1$)$ :

$$
\begin{aligned}
& \frac{\partial}{\partial x}\left[\mathrm{~K}_{x x} \frac{\partial H}{\partial x}+\mathrm{K}_{x y} \frac{\partial H}{\partial y}+\mathrm{K}_{x z} \frac{\partial H}{\partial z}\right]+\frac{\partial}{\partial y}\left[\mathrm{~K}_{y x} \frac{\partial H}{\partial x}+\mathrm{K}_{y y} \frac{\partial H}{\partial y}+\mathrm{K}_{y z} \frac{\partial H}{\partial z}\right] \\
& +\frac{\partial}{\partial z}\left[\mathrm{~K}_{z x} \frac{\partial H}{\partial x}+\mathrm{K}_{z y} \frac{\partial H}{\partial y}+\mathrm{K}_{z z} \frac{\partial H}{\partial z}\right]=\mathrm{S}_{s} \frac{\partial H}{\partial t}
\end{aligned}
$$

Equation (1) is the general groundwater movement equation of anisotropic media (Wang, 2011). Assuming that $\mathrm{x}=\mathrm{y}$ is substituted into Equation (1), the groundwater movement equation of transverse isotropic media is obtained, that is (Eq. 2):

$$
2 \frac{\partial}{\partial x}\left[2 \mathrm{~K}_{x x} \frac{\partial H}{\partial x}+\mathrm{K}_{x z} \frac{\partial H}{\partial z}\right]+\frac{\partial}{\partial z}\left[2 \mathrm{~K}_{z x} \frac{\partial H}{\partial x}+\mathrm{K}_{z z} \frac{\partial H}{\partial z}\right]=\mathrm{S}_{s} \frac{\partial H}{\partial t}
$$

Assuming that $\mathrm{K}_{\mathrm{x}}$ is the permeability coefficient in the horizontal direction and $\mathrm{K}_{\mathrm{z}}$ is the permeability coefficient in the vertical direction, the two-dimensional flow motion equation is shown as follows (Eq. 3):

$$
\frac{\partial}{\partial x}\left[\mathrm{~K}_{x} \frac{\partial H}{\partial x}\right]+\frac{\partial}{\partial z}\left[\mathrm{~K}_{z} \frac{\partial H}{\partial z}\right]=\mathrm{S}_{s} \frac{\partial H}{\partial t}
$$

In fact, the principle of three-dimensional flow and two-dimensional flow is essentially consistent, as shown in Figure 1.

In Figure 1, profile 1 is the $\mathrm{y}-\mathrm{z}$ profile of the geological body, and profile 2 is the $\mathrm{x}-\mathrm{z}$ profile of the geological body. The permeability coefficients are $K_{y}$ and $K_{z}, K_{x}$ and $K_{z}$, 
respectively. $K_{y}=K_{x}$ indicates that the penetration coefficient of the $y-z$ profile is consistent with that of the $\mathrm{x}-\mathrm{z}$ profile, indicating that the permeability coefficient of 3 dimension form is consistent with that of 2 dimension, that is, the essence of 3 dimension flow is consistent with that of 2 dimension flow, but only means that the form is different.

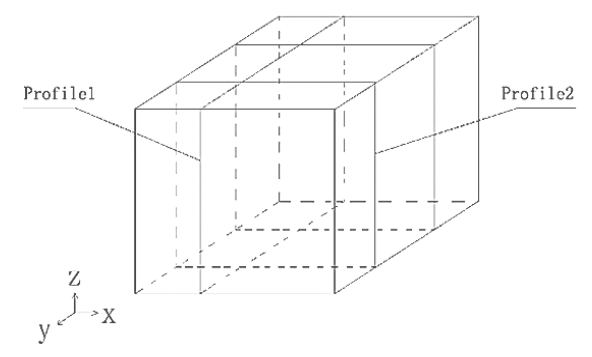

Figure 1. Two - dimensional, three - dimensional seepage model of the geological body

\section{The theory of shallow groundwater level based on remote sense groundwater assessment}

In this paper, the concept of "shallow layer" in the shallow groundwater is the first aquifer, most of which is the diving layer that is the first stable aquifer below the surface, sometimes the upper stagnant water, sometimes the pressure water, in short, the first aquifer below the surface. In order to obtain the initial groundwater level of bedrock islands, the study used the assessment of groundwater potential by RS method (GRSFAI method) to obtain the initial water level. And lithology index, slope index, relief index, soil humility index, land temperature index, vegetation fraction index and other indexes were selected to establish the model. The equation of score, $\mathrm{S}$, is shown as follows (Eq. 4) (Deepesh et al., 2010; Lee et al., 2012; Deng et al., 2013):

$$
\mathrm{S}=\sum_{\mathrm{i}}^{\mathrm{n}} \mathrm{W}_{\mathrm{i}} \bullet \mathrm{Y}_{\mathrm{i}}
$$

where $S$ is the score of assessment of groundwater potential, the $Y_{i}$ values are different kinds of indexes. And the $\mathrm{W}_{\mathrm{i}}$ values are the weights of indexes.

The assessment score, $\mathrm{S}$, of shallow groundwater enrichment grade and the water volume, $\mathrm{V}$, in the measured well can be obtained by applying the improved GRSFAI method based on RS-image grayscale statistics and cluster analysis method, and the fitting curve of the two can be finally obtained. And the general formula is $S=a \cdot e^{b v}$. The average the amount of water in a well or spring in terms of its area, the study can get the formula (Eq. 5):

$$
\mathrm{h}=\frac{1}{\Delta \mathrm{s} \cdot \mathrm{b}} \ln \frac{\mathrm{S}}{\mathrm{a}}
$$

where $\mathrm{h}$ is the buried depth per unit water level, as shown in Figure 2, and is the elevation from the level groundwater to 2 meters above the groundwater surface. Then, the study can obtain a water level of groundwater: $\mathrm{D}=\mathrm{DEM}-\mathrm{h}$. The average $\mathrm{V}$ water 
flow is directly represented by the actual unit water level buried depth $\mathrm{h}$ at this point, and the formula $(E q .6)$ is

$$
\mathrm{S}=\mathrm{a}_{1} \cdot \mathrm{e}^{\mathrm{b}_{\mathrm{l}} \mathrm{h}}
$$

Next, by fitting the evaluated score, S, with the buried depth, h, of unit water level, the coefficients $a_{1}$ and $b_{1}$ are obtained. Then, using ENVI software (Duan, 2016), MATLAB software or EXCEL software to calculate the value of $h$ in the entire research area, or the key points of the research area. And the water level of groundwater: DEM-h is used as the initial water level data matrix of the first aquifer in this area. The initial digital, D, is introduced into the GMS software or TOUGH software to simulate and predict the shallow groundwater flow. Thus, the difficulty of obtaining the initial water level elevation of the bedrock islands is overcome.

The specific research route of this paper is shown in Figure 3.

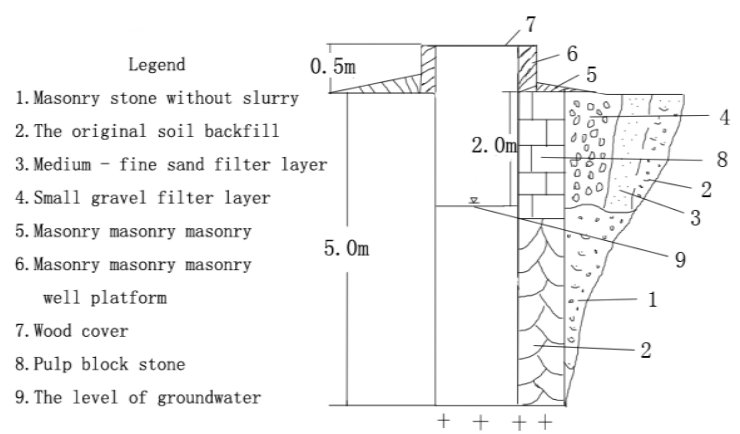

Figure 2. Diagram of the well

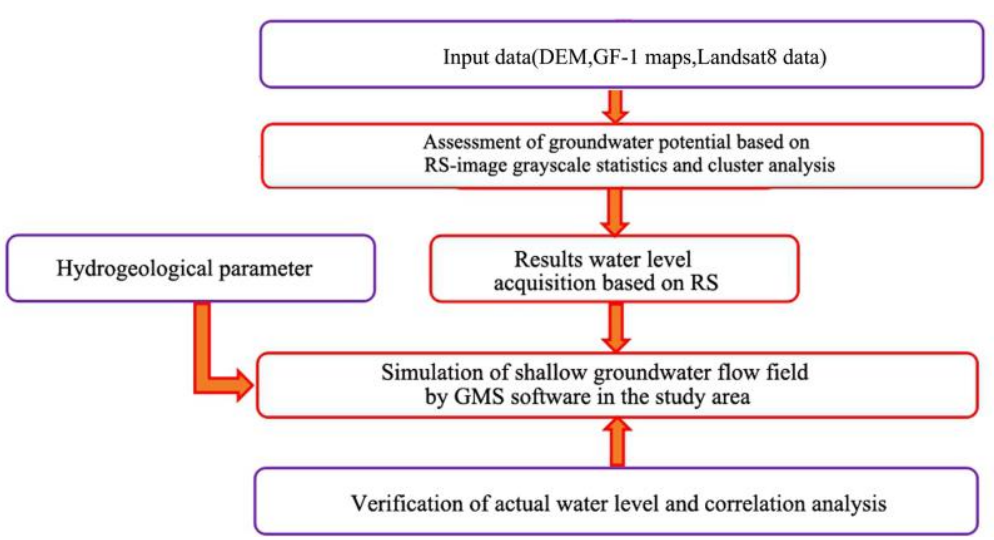

Figure 3. The research idea flow chart

\section{Hydrogeological parameters of the study area}

Waiilingding island is located in the northeast of Zhuhai city, Guangdong province, China, extending between $22^{\circ} 5^{\prime} 17.16^{\prime \prime} \mathrm{N}$ and $22^{\circ} 6^{\prime} 57.54^{\prime \prime} \mathrm{N}$ latitude and $114^{\circ} 1^{\prime} 11.19^{\prime \prime} \mathrm{E}$ and $114^{\circ} 3^{\prime} 15.40^{\prime \prime} \mathrm{E}$ longitude, shown as Figure 4. Rainfall situation of the island is 
following, the rainfall can be divided into high and dry seasons. The rainfall during the period from April to September takes up more than $80 \%$ of the annual rainfall. The average monthly rainfall is between 200 and $350 \mathrm{~mm}$. In addition, the whole island is about 3,200 meters long, about 2,400 meters wide, and the narrowest place is only 1,070 meters, with an area of $4.33 \mathrm{~km}^{2}$. The coastline around the island is $12.3 \mathrm{~km}$. And the coastline is changeable, the geomorphology changes is rich, the island landscape coexists, has many kinds of bay and beach. Wailingding island is very rocky outcrop. In the valley, there are a lot of granite eggs with diameter of 2 to 4 meters.

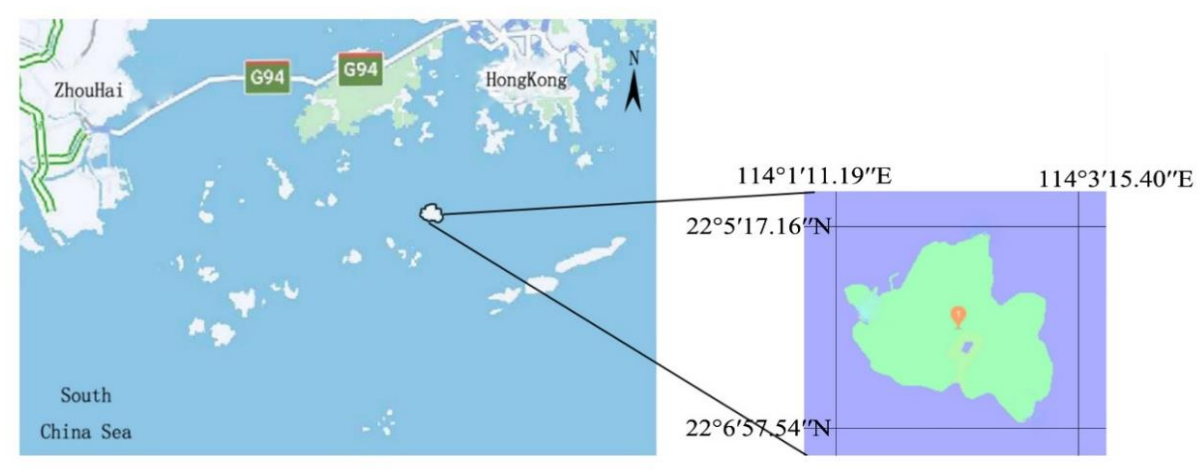

Figure 4. The map of the study area

The island's geological structure is simple, mostly granite. From the top to the bottom of the island, it can be divided into three layers, namely the weathered layer soil, vegetation cover, and bare rock, semi-weathered layer and granite bedrock bottom layer. Moreover, the joints of rocks are relatively developed, but the density is not uniform, and there are large faults. The discovery of groundwater in the large sump pit and the wells and springs previously used by people on the island has indicated the existence of groundwater, but the capacity is limited. The islands are surrounded by seawater, and the only source and supply of groundwater is rainwater. Underground cave or fissure, that is, a closed can accumulate a certain amount of water, and also known as island freshwater mushroom body or freshwater lens, forming the groundwater in this island for many years.

\section{Software simulation of shallow groundwater flow field based on remote sense}

\section{Setting hydrogeological parameters in GMS software}

According to the test values of hydrogeological parameters given in the Hydrogeological handbook (Wang, 2012), the Dam project handbook (Mao, 2009) and the Simulation of pollutant migration in groundwater (Zheng, 2009), The parameters such as horizontal permeability coefficient, vertical permeability coefficient, water availability, water storage coefficient and anisotropic parameters were input into the groundwater simulation software, as shown in Figure 5. And the Figure 6 was a lithological sample of the study area.

Then, the study used the Wailingding island area of Google map as the base of software simulation. Large areas of groundwater on the island were delineated and potholes (or small lakes) were formed, and there were wells and springs in the study area. The recharge in this region is $0.000493 \mathrm{~m} / \mathrm{d}$. Due to the particularity of the 
bedrock island, the coastal edge of bedrock is in the form of the freshwater mushroom body, which can set the bedrock coastline as the fixed head boundary by the SEAWATER module of GMS software (Pang and Gao, 1988). And the coastline of the island is used as the boundary of bedrock islands.

\begin{tabular}{|c|c|c|c|c|c|c|c|c|c|c|c|}
\hline ID & Name & Color/Pattem & Transparency $(\%)$ & $\begin{array}{c}\text { Horizontal k } \\
(\mathrm{m} / \mathrm{d})\end{array}$ & $\begin{array}{l}\text { Vertical k } \\
(\mathrm{m} / \mathrm{d})\end{array}$ & Honiz. anisotropy & \begin{tabular}{|c} 
Vert. anisotropy \\
$(\mathrm{Kh} / \mathrm{Kv})$
\end{tabular} & \begin{tabular}{|c|}
$\begin{array}{c}\text { Specific storage } \\
(1 / \mathrm{m})\end{array}$ \\
\end{tabular} & Specific yield & Long. disp. & Porosity \\
\hline & & 5 & & & & & & & & & \\
\hline 1 & Sandy soil & $\square$ & 0.0 & 0.864 & 0.864 & 1.0 & 1.0 & 0.0013 & 0.06 & 0.0 & 0.3 \\
\hline 2 & diff granite1 & $\square$ & 0.0 & 0.01296 & 0.01296 & 1.0 & 1.0 & 0.000069 & 0.0036 & 0.0 & 0.3 \\
\hline 3 & diff granite2 & $\square$ & 0.0 & 0.005184 & 0.005184 & 1.0 & 1.0 & $3.3 e-006$ & 0.0021 & 0.0 & 0.3 \\
\hline 4 & grante & ] & 0.0 & $1.728 \mathrm{e}-007$ & $1.728 \mathrm{e}-007$ & 1.0 & 1.0 & 3.0e-006 & 0.003 & 0.0 & 0.3 \\
\hline 5 & Shingle & $\square$ & 0.0 & 86.4 & 864.0 & 1.0 & 10.0 & 3.0e-006 & 0.03 & 0.0 & 0.3 \\
\hline
\end{tabular}

Figure 5. Various lithologic hydrogeological parameters

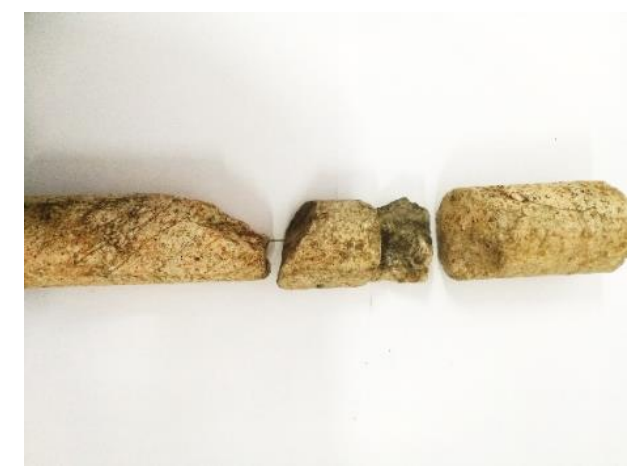

Figure 6. A lithological sample of the study area

\section{Water level distribution parameters based on remote sense}

Based on the assessment score value, $\mathrm{S}$, of the results of shallow groundwater potential in the study area (Xu et al., 2018) which was shown as Figure 7 (Xu et al., 2018). And the basal remote sensing data (DEM, GF-1 data, Landsat 8 data and so on) can be download from http://www.rscloudmart.com or http://www.gscloud.cn/sources. The actual unit water level depth $h$ of this point is directly expressed according to the average $\mathrm{V}$ water volume, that is, $\mathrm{S}=\mathrm{a}_{1} \cdot \mathrm{e}^{\mathrm{blh}}$. Subsequently, the evaluated score $\mathrm{S}$ was fitted with the buried depth $h$ of unit water level, and the coefficients $a_{1}$ and $b_{1}$ were obtained. Then, using ENVI software or MATLAB to get the level of groundwater of the first layer, $\mathrm{D}=\mathrm{DEM}-\mathrm{h}$.

According to Table 1, the study can obtain the formula (Eq. 7) of fitting curve of $\mathrm{h}$ and S (Zheng et al., 2009; Deng et al., 2013):

$$
\mathrm{S}=0.427 \mathrm{E}^{0.239 \mathrm{H}}
$$

And $R^{2}=0.8472$. It showed that the fitting degree of $h$ of water level per unit area per unit time in wells or springs and the $S$ of assessment of shallow groundwater potential by remote sensing was good. Next, the formula for calculating $\mathrm{h}$ of the evaluated score value $\mathrm{S}$ of each point can be deduced reversely according to the formula (Eq. 8): 


$$
\mathrm{h}=\frac{1}{0.239} \ln \left(\frac{\mathrm{S}}{0.427}\right)
$$

In addition, the water level of shallow groundwater was $\mathrm{D}$, and the surface elevation valued DEM and h were (Eq. 9):

$$
\mathrm{D}=\mathrm{DEM}-\mathrm{H}
$$

Then, the study introduced the initial level D of the simulation of the shallow subsurface flow field of the bedrock island into the GMS software. And the study set the parameters of layers and starting heads which were shown in Figure 8.

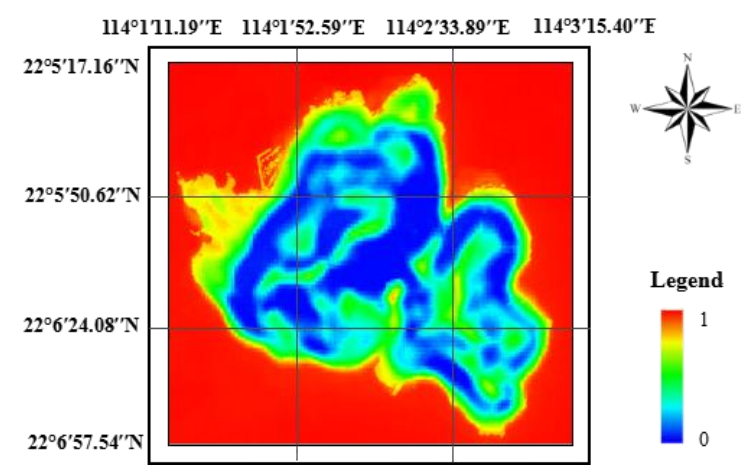

Figure 7. Level results of assessment of groundwater potential in the study area (Xu et al., 2018)

Table 1. Scores of shallow groundwater potential and depth of water level per unit

\begin{tabular}{c|c|c|c|c}
\hline Number & Yield of water/(L· $\left.\mathbf{s}^{-\mathbf{1}}\right)$ & S of assessment & $\mathbf{h} /(\mathbf{m})$ & DEM-h = D /(m) \\
\hline$\# 1$ & About 1.26 & 0.655 & 1.26 & 1.79 \\
$\# 2$ & $0.20 \sim 0.40$ & 0.415 & 0.30 & -0.12 \\
$\# 3$ & $0.20 \sim 0.30$ & 0.414 & 0.25 & -0.13 \\
$\# 4$ & About 1.00 & 0.620 & 1.00 & 1.56 \\
$\# 5$ & About 3.22 & 0.830 & 3.22 & 2.78 \\
$\# 6$ & $0.55 \sim 0.60$ & 0.510 & 0.59 & 0.743 \\
$\# 7$ & $0.23 \sim 0.30$ & 0.426 & 0.25 & -0.01 \\
$\# 8$ & About 1.50 & 0.650 & 1.50 & 1.76 \\
\hline
\end{tabular}

Establishment of shallow groundwater model by using GMS software (Liu and Zhang, 2015)

[STEP1]: Setting the basic hydrogeological parameters of the study area as shown in Figure 5 and setting the parameters of layers and staring heads. Then, setting the supply item and discharge item according to the water level geological data and actual survey data. And the recharge is $0.000493 \mathrm{~L} / \mathrm{d}$. The recharge was $0.00603 \mathrm{~L} / \mathrm{d}$ at the location of puddles and small lakes. And setting up the corresponding well-pumping water. The supply area was shown in Figure 9. 


$$
-14188 \text { - }
$$

[STEP2]: Inputing reproduction, and then inputing the region of the DEM (Dong et al., 2008) which can download freely http://www.gdem.aster.ersdac.or.jp/index.jsp. TIF file was shown in Figure 10. And drawing the corresponding CAD reproduction, convenient area of the surface waters in the region, islands area, block partition and edge boundaries.

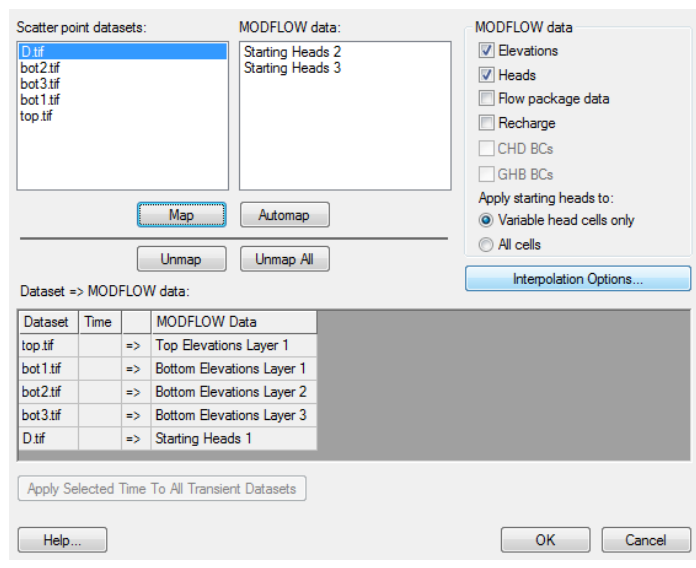

Figure 8. Setting parameters of layers and starting heads

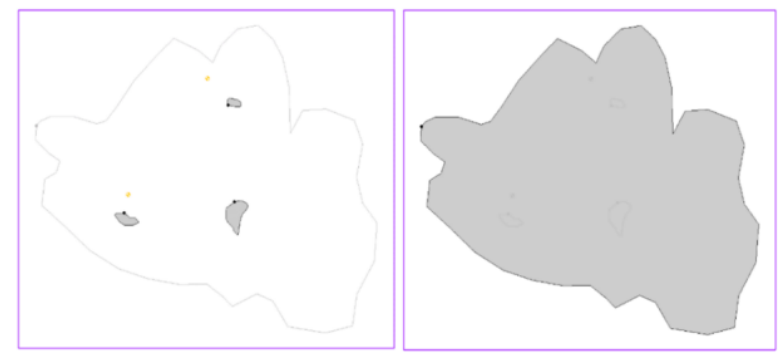

Figure 9. Setting of the supply area

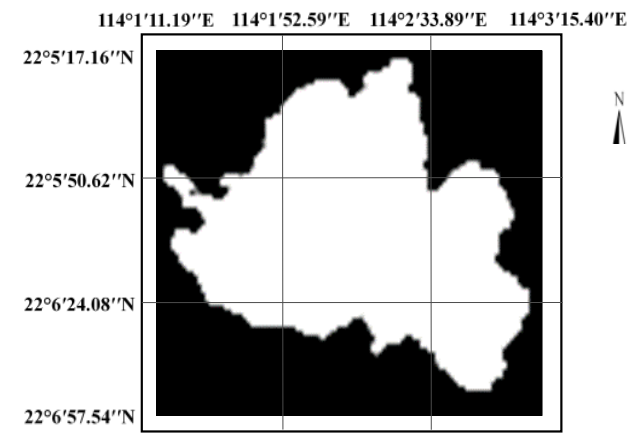

Figure 10. TIF file of DEM in the study area

[STEP3]: The mesh generation and model calculation.

The study imported the TIF file of the initial water level, D, into the GMS software and converted it into a scatter in the GMS software, as shown in Figure 11. And the study used the direct current method to detect the stratigraphic stratification of the 
island, as shown in Figure 11. The results showed that the thickness of the blue region with low apparent resistivity was about 1 2 $\mathrm{m}$. The thickness of the medium apparent resistivity area in Figure 12 was about $2 \sim 5 \mathrm{~m}$, that was, $5 \sim 7 \mathrm{~m}$ underground. It's green and yellow parts that were shown on the Figure 12. Moreover, the high apparent resistivity area below, combined with the actual survey data, should correspond to the underlying granite bedrock, and the orange and red parts were shown in Figure 12. The ground penetrating radar (GPR) was used to study the stratigraphic stratification results of the direct current method. The results were shown in Figure 13. According to the difference in the dielectric constant of the plastid, the thickness range of the surface layer is about 1 2 $\mathrm{m}$, as shown in Figure 13.

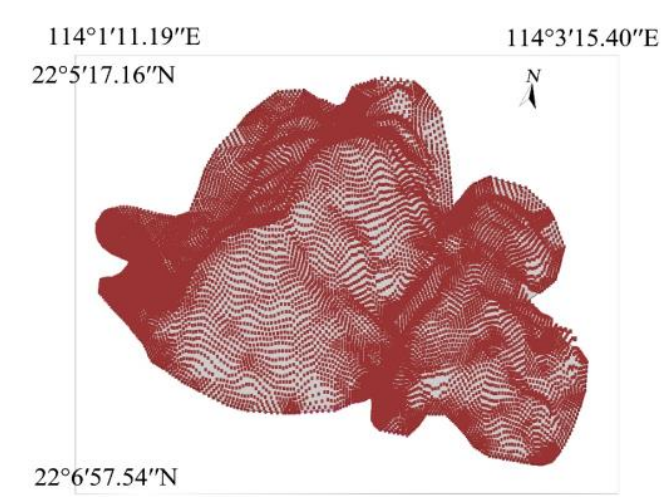

Figure 11. A scatter diagram of $D$

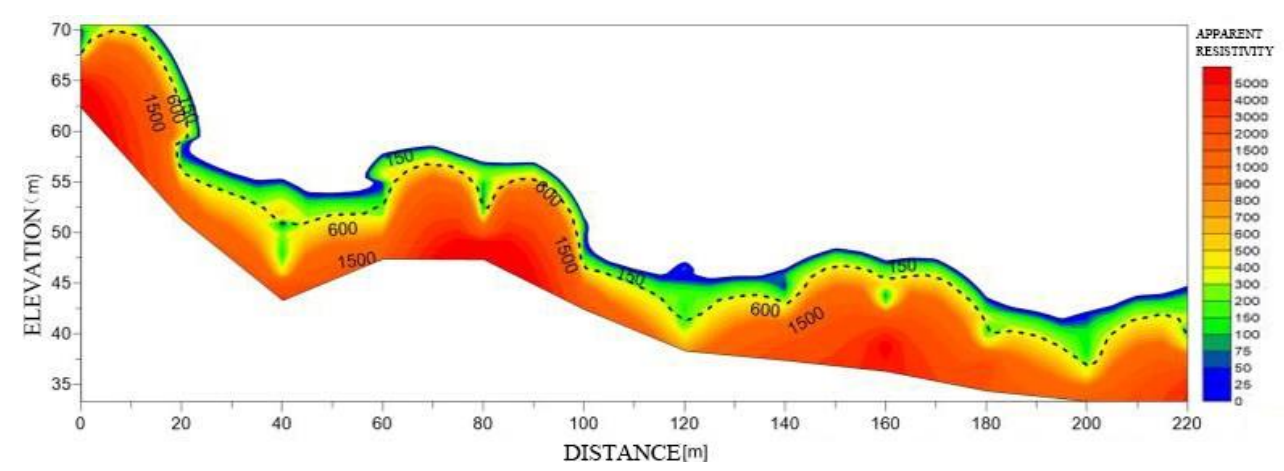

Figure 12. The result of detection by DC method

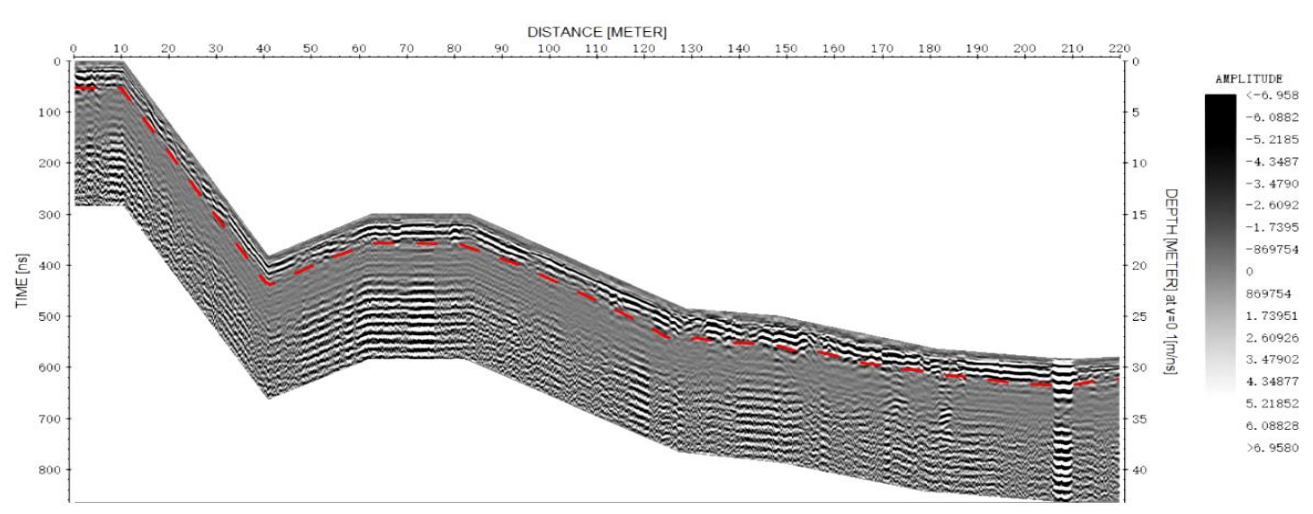

Figure 13. The result of detection by GPR method 
It is the completely weathering granite layer in the ground. Next, another 5-7 metre underground stratum can be clearly shown in the diagram, combined with the actual survey data, can correspond to partly weathering granite layer. Then, the part below 5 7 $m$ underground is obviously different from the above stratum. Combined with the actual survey data, it can be corresponding to the bottom of the granite bedrock. Thus, the study can set the formation parameters according to the results of Figure 5, Figure 12 and Figure 13. Then, the mesh was segmented, as shown in Figure 14. Next, the study used the MODFLOW program to calculate the flow field distribution in the study area.

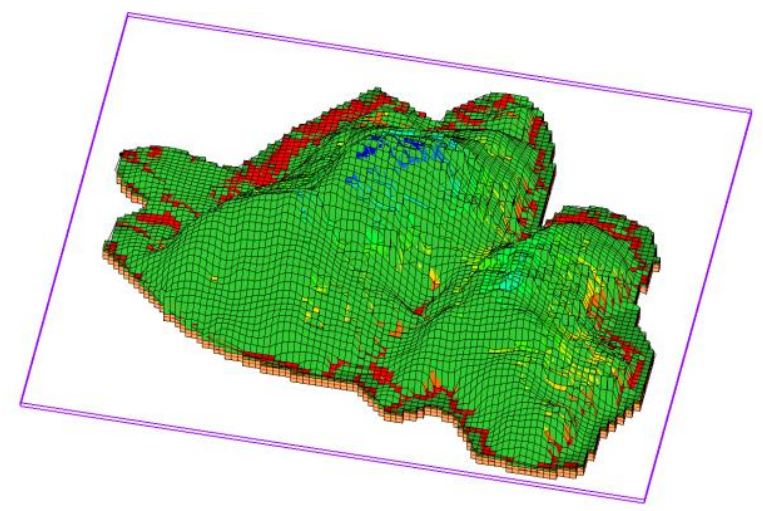

Figure 14. Schematic diagram of mesh subdivision

\section{Results and Analysis}

\section{Simulation results of shallow groundwater flow field based on remote sense}

The results of simulation by using GMS were shown the Figure 15 and Figure 16. They showed that the level of groundwater in this island. The water level around the island was low.

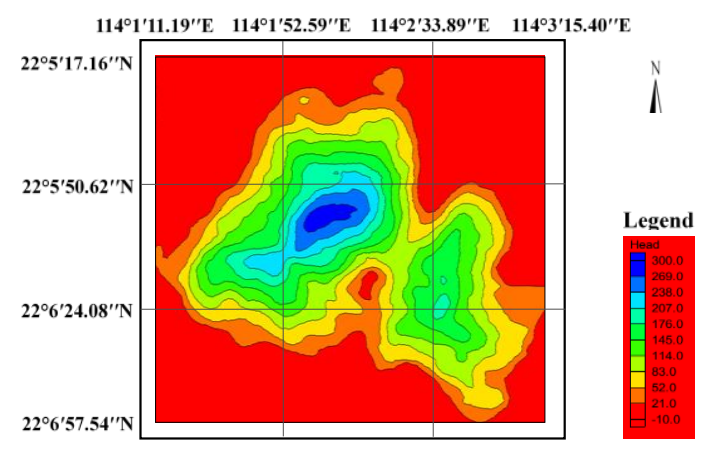

Figure 15. Simulation results of island shallow groundwater by using GMS software

High water levels in the middle and southeast of the island indicated a water-storage structure. And the study can see the shallow groundwater flow field that flows outward from the middle of the island, outward from the southeast, and surrounding flow towards the middle of the island. The lower water level in the south-central part of the island and combined with its analysis of water yield showed that the area was easy to fetch water. 
Figure 15 can clearly reflect the water level distribution of shallow groundwater. Moreover, Figure 16 can clearly reflect the simulation results of the shallow groundwater flow field. From the perspective of water level, the water level of this island tends to be high in the middle and southeast and low in the periphery. Figure 17 can reflect the water level distribution of the whole island in 3 dimensions. Figure 16 can reflect the flow field trend of shallow groundwater of the island, which flowed from the middle to the outside, from the southeast to the outside, and from the surrounding to the inside of the island. The reason for the trend of the underground flow field to the island should be the existence of seawater. Four points, the first line, about $12 \mathrm{~m}$ in length, was located in the puddle above the road next to the first point coordinates: $\mathrm{N} 22.096674^{\circ}, \mathrm{E} 114.038623^{\circ}, \mathrm{H} 33.2 \mathrm{~m}$. The result is shown as Figure 18, which can show there should be bedrock fissure water storage in the underground 5 13 $\mathrm{m}$ range by analyzing the different apparent resistivity of this area. Also, spring water emerged about $10 \mathrm{~m}$ below this area, N22.097272 ${ }^{\circ}, \mathrm{E} 114.038793^{\circ}, \mathrm{H} 21.4 \mathrm{~m}$. It was shown as Figure 19.

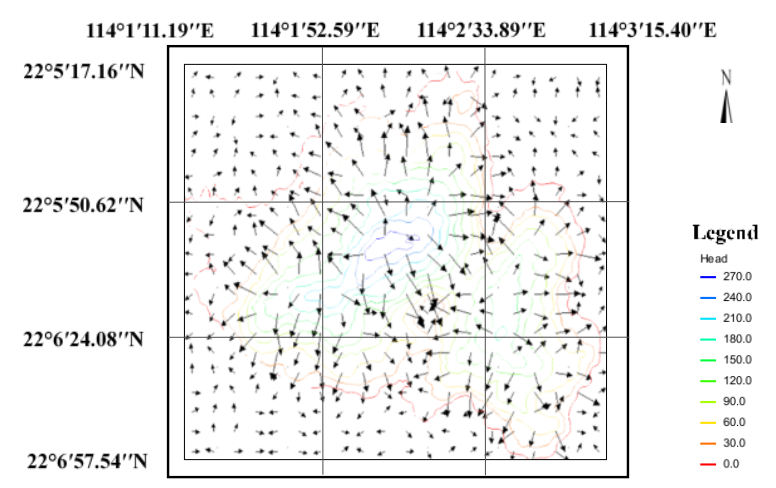

Figure 16. Simulation results of island shallow groundwater flow

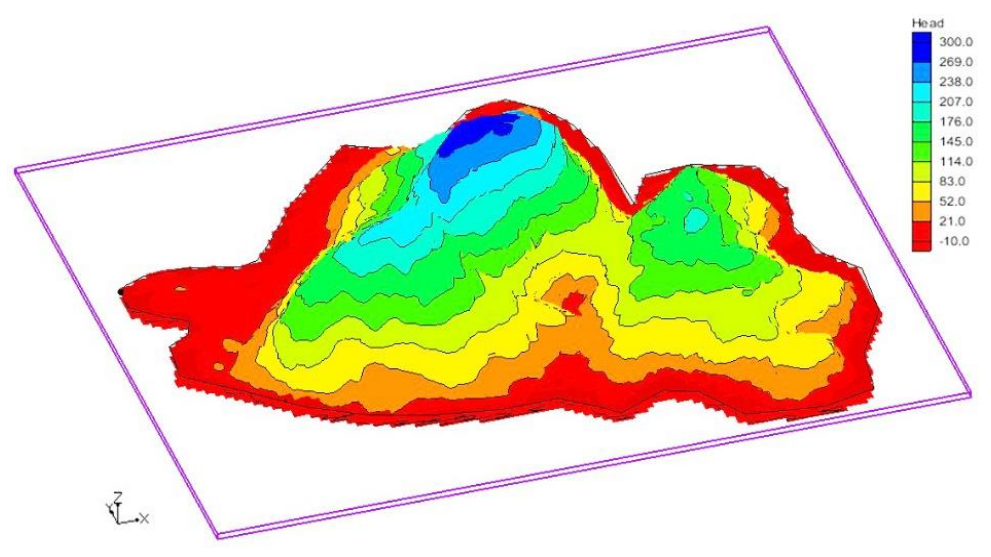

Figure 17. 3D results of simulation groundwater level of the island

According to the data of springs and wells on the island, and the field survey and the evidence results of DC detection, the unit water level value of the corresponding point can be obtained, and the corresponding relationship between the simulated value and the actual value can be reflected in Table 2 . 


$$
-14192 \text { - }
$$

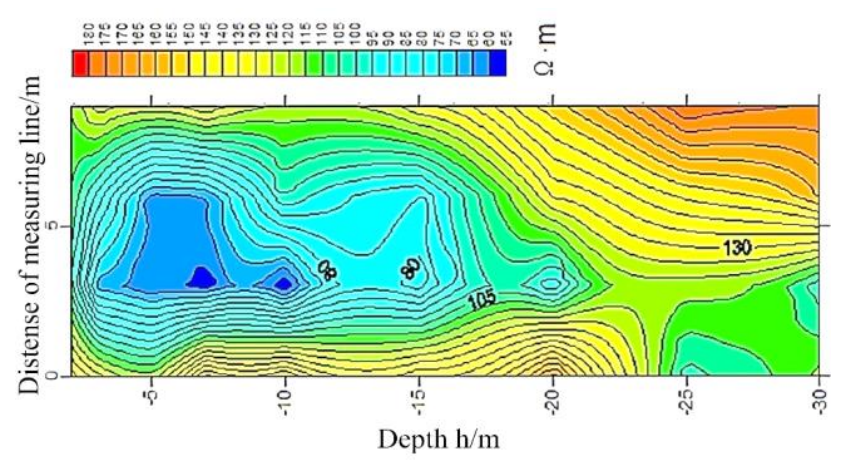

Figure 18. The profile of DC detection in the study area
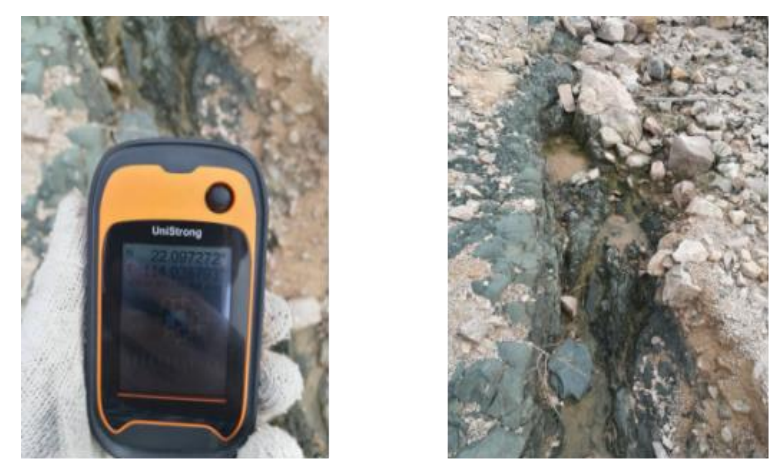

Figure 19. Actual view of spring water outcropping in the research area

Table 2. The results of simulation and the D of points

\begin{tabular}{c|ccc|c|ccc}
\hline Point & S & $\begin{array}{c}\text { DEM- } \\
\mathbf{h}=\mathbf{D} /(\mathbf{m})\end{array}$ & D of simulation/(m) & Point & S & $\begin{array}{c}\text { DEM- } \\
\mathbf{h}=\mathbf{D} /(\mathbf{m})\end{array}$ & D of simulation/(m) \\
\hline 1 & 0.529 & 29.4 & 31.79 & 5 & 0.483 & 25.65 & 20.2 \\
2 & 0.592 & 23.1 & 24.97 & 6 & 0.514 & 22.78 & 17.1 \\
3 & 0.640 & 21.5 & 22.73 & 7 & 0.531 & 23.69 & 19 \\
4 & 0.458 & 26.2 & 29.41 & 8 & 0.689 & 17.01 & 14.3 \\
\hline
\end{tabular}

\section{Correlation analysis of simulation data and the measured water level value}

The study analyzed the results of simulation and D more carefully by using a correlation analysis chart between the D and D of simulation that was shown as Figure 20. And it was easy to see the two values were positively correlated.

The correlation between the simulated value and the actual water level of unit time and unit area D was positive and linear, and $\mathrm{R}^{2}=0.862(\mathrm{P}<0.05)$, as shown in Figure 20, indicating that the simulation results were consistent with the actual water level results and the error accuracy was also good. Therefore, the initial water level obtained based on remote sensing assessment of shallow groundwater was imported into GMS software, and corresponding hydrogeological parameters of islands were added. The model of flow field simulation can reflect the distribution of real shallow groundwater flow field within a certain precision range. Therefore, the difficulty of obtaining the initial water level of bedrock islands was solved based on an assessment of shallow groundwater by RS technology and groundwater simulation technology. 


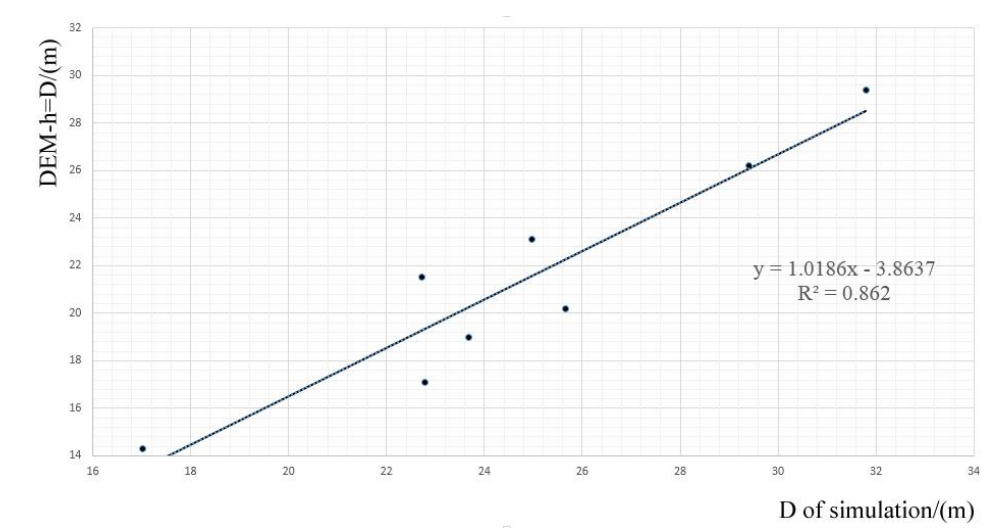

Figure 20. A correlation analysis chart between the $D$ and $D$ of simulation

\section{Discussion}

This study used ENVI software to convert remote sensing satellite DEM data into TIF files and imported them into GMS software, which improved the accuracy of island geological body model. Using the DEM data to model the geological model of island was more accurate than the traditional method which based on use of some well data. And this paper combined high-precision remote sensing data with shallow groundwater simulation, which was an innovation in methods.

In addition, the score, $\mathrm{S}$, of assessment groundwater potential was fitted to the depth, $\mathrm{h}$, of the unit water level, which was used to obtain the initial water level, D, of shallow groundwater. Then, D was introduced into the GMS software. And using the meteorological and hydrogeological data, geological data and geophysical data of the study area, the simulation of shallow groundwater flow field was carried out, which solved well the difficulty of obtaining the initial water level of shallow groundwater in a small bedrock island and simulated well the shallow groundwater flow of a small bedrock island. Also, the results of the shallow groundwater simulation based on RS are correlated with the actual water level of wells or springs and the geophysical data.

\section{Conclusions}

This paper studied the related theories of groundwater in a bedrock island, which proposed to use remote sensing assessment technology of shallow groundwater to get the initial water level of groundwater in the bedrock island so that the study can simulate the flow of groundwater in this island. Finally, the following conclusions can be drawn:

(1) It was concluded that the form of fresh water on the bedrock islands is mainly in the form of "mushroom body", which is accompanied by the form of "lens body". If the groundwater flow field can be simulated, the movement equation of bedrock islands can be expressed as transverse isotropy (isotropy in horizontal direction), and the main recharge of island groundwater is rainfall.

(2) By combining remote sensing data with groundwater simulation, DEM data was transformed into TIF files by ENVI software, which was then introduced into GMS software, and the stratification of island strata determined by geophysical exploration technology combined with actual survey data improved the accuracy of geological body simulation. 
(3) The results of assessment shallow groundwater based on remote sensing was fitted with the water level of the area to get the initial water level. This method can solve the problem that the initial water level of the bedrock islands is difficult to obtain, and results the simulation flow groundwater of the island have good accuracy.

Acknowledgements. This work was supported by Development Program of China: research and demonstration of ecological construction of typical islands in the South China Sea and the monitoring technology of ecological things in the South China Sea, NO.2017YFC0506304. And based on remote sensing geology survey, the application information extraction and drawing of national defense construction, NO.DD2016007637.

\section{REFERENCES}

[1] Alfaro, P., Liesch, T., Goldscheider, N. (2017): Modelling groundwater over-extraction in the southern Jordan Valley with scarce data. - Hydrogeology Journal 25(5): 1319-1340.

[2] Barazzuoli, P., Nocchi, M., Rigati, R. (2008): A conceptual and numerical model for groundwater management: A case study on a coaster aquifer in southern Tuscany, Italy. Hydrogeology Journal 16(1): 1557-1576.

[3] Deepesh, M., Madan, K. J., Bimal, C. M. (2010): Assessment of Groundwater Potential in a Semi-Arid Region of India Using Remote Sensing,GIS and MCDM Techniques. Water Research Management 25: 1359-1386.

[4] Deng, Z. D., Ye, X., Long, F., Yu, D. H., Guan, H. J., Zhang, B. S. (2013): Construction and investigation of groundwater remote sensing fuzzy assessment index. - Chinese Journal of Geophysics 56(11): 3908-3916.

[5] Dong, Y. H., Li, G. M., Guo, Y. H. (2008): Application of SRTM3 DEM in regional groundwater numerical simulation. - Geotechnical Investigation \& Surveying 11(1): 4144.

[6] Duan, H. J., Deng, Z. D., Deng, F. F., Wang, D. Q. (2016): Assessment of groundwater potential based on multicriteria decision making model and decision tree algorithms. Mathematical Problems in Engineering 1(1): 1-11.

[7] EI-Kadi, A., Tillery, S., Whinier, R. B. (2014): Assessing sustainability of groundwater resources on Jeju Island, South Korea, under climate change, drought, and increased usage. - Hydrogeology Journal 22(3): 625-642.

[8] Lathashri, U. A., Mahesha, A. (2016): Groundwater sustain-ability assessment in coastal aquifers. - Journal of Earth System Science 125(6): 1-16.

[9] Lee, S., Kim, Y. S., Oh, H. J. (2012): Application of a weights-of-evidence method and GIS to regional groundwater productivity potential mapping. - Journal of Environmental Management 96(1): 91-105.

[10] Liu, C. W., Lin, C. N. (2006): Sustainable groundwater management in Kinmen Island. Hydrological Processes 20(20): 4363-4372.

[11] Liu, L. H., Zhang, S. Q. (2015): Construction of 3D visualization model of groundwater system under multiple constraints based on GMS. - Journal of University of Chinese Academy of Sciences 32(4): 506-511.

[12] Long, J. C. S., Remer, J. S., Wilson, C. R. (1982): Porous media equivalents for networks of discontinuous fractures. - Water Resource Research 18(3): 645-658.

[13] Lu, Y. D. (2007): Report on hydrogeological characteristics of east island new area of Zhanjiang economic and technological development zone. - Zhanjiang: The first team of hydrological engineering geology of Guangdong geological bureau 1(1): 1-12.

[14] Mao, C. X., Chen, P. (1984): Calculation and test of rock fracture seepage flow. Scientific Research on Water Conservancy and Transportation 1(3): 29-37. 
[15] Mao, C. X. (2009): Dam project handbook. - China water conservancy and hydropower press 1(1): 1-105.

[16] McCartney, M. P., Houghton-Carr, H. A. (2018): An assessment of groundwater recharge on the Channel Island of Jersey. - Journal of the Chartered Institution of Water and Environmental Management 12(6): 445-451.

[17] Mehdizadeh, S. S., Karamalipour, S. E., Asoodeh, R. (2017): Sea level rise effffect on seawater intrusion into layered coastal aquifers (simulation using dispersive and sharpinterface approaches). - Ocean \& Coastal Management 138: 11-18.

[18] Pang, C. H. (1987): Distribution characteristics of groundwater resources in bedrock islands along the east coast of China: a case study of Miaodao islands. - Geoscience (in Chinese) 7(3): 291-299.

[19] Pang, C. H., Gao, M. (1988): Groundwater resources and environment in bedrock islands: a case study of Miaodao islands. - Survey science and technology (in Chinese) 1(3): $27-$ 30.

[20] Pang, Z. H., Gao, M. (1988): The groundwater resources and environment of the bedrock island-take the temple islands as an example. - Site Investigation Science and Technology 3(1): 27-30.

[21] Rosemary, W. H. C., Greg, M. P., Ronald, L. H. (2009): An unconfined groundwater model of the Death Valley Regional Flow System and a comparison to its confined predecessor. - Journal of Hydrology 5(6): 316-328.

[22] Tan, J. H., Lei, H. W. (2017): Three - dimensional TOUGH2 model and simulation based on GMS. - Journal of Jilin University (geoscience edition) 47(4): 1229-1235.

[23] Teng, J. B., Liu, W. F., Zhou, W. (2015): A numerical simulation study on the groundwater of alluvial continental islands-east island as an example. - Environmental impact assessment 37(1): 59-63.

[24] Tian, K. M., Wang, L. (1989): Study and evaluation of anisotropic fracture medium permeability. - Scholastic press 1(1): 1-89.

[25] Wang, X. S., Wan, L. (2011): Equation for Groundwater Flow. - Beijing: Geological Publishing House 1(1): 1-15.

[26] Wang, H. L. (2012): A review of numerical simulation of fracture water seepage in bedrock. - World nuclear geoscience 29(2): 85-91.

[27] Wang, M., Yin, Y. P., Wen, D. G. (2012): Hydrogeological handbook. - Geological publishing house 1(1): 1-95.

[28] Wen, H. H. (2013): Study on groundwater circulation law and reasonable exploitation and utilization in Leizhou peninsula. - China University of Geosciences 1(1): 1-56.

[29] Xu, H. L., Wang, D. Q., Deng, Z. D., Ding, Z. B., Liu, Z. X., Wang, G. Y., Ni, B. R. (2018): Application of remote sensing fuzzy assessment method in groundwater potential in Wailingding Island. - The Journal of Supercomputing 1(1): 1-13.

[30] Yi, L. X., Ma, B., Liu, L. L. (2016): Simulation of groundwater-seawater interaction in the coastal surficial aquifer in Bohai Bay, Tianjin, China. - Estuarine Coastal \& Shelf Science 177(1): 20-30.

[31] Zheng, C. M., Sun, J. Y. (2009): Simulation of pollutant migration in groundwater. Higher publishing house education 1(1): 1-85.

[32] Zhou, P. P., Li, M., Lu, Y. D. (2017): Study on the groundwater sustainable problem by coastal aquifer numerical simulation in a multi-layered system of Zhanjiang, China. Indian Academy of Sciences 102(1): 1-26.

[33] Zhou, P. P., Li, M., Lu, Y. D. (2017): Hydrochemistry and isotope hydrology for groundwater sustainability of the coastal multilayered aquifer system (Zhanjiang, China). - Geofluids: 1-19. 